\title{
Radiative Stabilization of Trimethylsilyl Adduct Ions
}

\author{
Ron Orlando, D. P. Ridge, and Burnaby Munson \\ Department of Chemistry and Biochemistry, University of Delaware, Newark, Delaware, USA
}

Ketones and phenol react with trimethylsilyl ions to form adduct ions by radiatively or collisionally stabilized addition reactions, in contrast to aliphatic alcohols and ethers, which react with trimethylsilyl ions to form adduct ions by a rapid two-step process. Secondorder rate constants for the addition of trimethylsilyl ions to acetone were independent of pressure from $3 \times 10^{-7}$ to $50 \times 10^{-7}$ torr at room temperature; consequently, the adduct ions, $[\mathrm{M}+73]^{+}$, are formed primarily by radiatively stabilized addition in these ion cyclotron resonance experiments. ( $\mathrm{Am}$ Soc Mass Spectrom 1990, 1, 144-148)

$\mathrm{T}$ The usefulness of tetramethylsilane (TMS) as a reagent gas for chemical ionization mass spectrometry (CIMS) depends on the abundant trimethylsilyl adduct ions, $[\mathrm{M}+73]^{+}$, formed with compounds containing a variety of functional groups [1-4]. For aliphatic alcohols and ethers, these adduct ions are formed by rapid two-step processes that involve the formation of intermediate ions, $\left(\mathrm{CH}_{3}\right)_{3} \mathrm{SiOH}_{2}{ }^{+}$and $\left(\mathrm{CH}_{3}\right)_{3} \mathrm{SiOHR}^{+}[5,6]$, but for a number of other oxygen-containing compounds (including aldehydes, ketones, phenols, and methyl phenyl ether), sample adduct ions appear to be formed by direct addition $[3,6,7]$. The mechanism for such an addition must involve a reversible association reaction,

$$
73^{+}+\mathrm{M} \stackrel{k_{1}}{\rightleftarrows}[\mathrm{M}+73]^{+*}
$$

followed by stabilization by collision with a neutral molecule,

$$
[\mathrm{M}+73]^{+*}+\mathrm{M} \stackrel{k_{\mathrm{c}}}{\rightarrow}[\mathrm{M}+73]^{+}
$$

or

$$
[\mathrm{M}+73]^{+*}+\mathrm{TMS} \stackrel{k_{\mathrm{c}}^{\prime}}{\rightarrow}[\mathrm{M}+73]^{+}
$$

or by radiative emission,

$$
[\mathrm{M}+73]^{+*} \stackrel{k_{\mathrm{r}}}{\rightarrow}[\mathrm{M}+73]^{+}+h \nu
$$

When $\mathrm{M}$ is an aliphatic alcohol or alkyl ether, the association complex can eliminate an olefin exothermically and consequently does not survive long enough

Address reprint requests to Burnaby Munson, Department of Chemistry and Biochemistry, University of Delaware, Newark, DE 19716. for stabilization to occur. For other M's, however, the occurrence of the direct addition of trimethylsilyl ions indicates long lifetimes with respect to dissociation for the association complexes.

\section{Experimental}

Ion cyclotron resonance (ICR) experiments were performed with an instrument using a frequency-swept capacitance bridge that has been previously described [8-10]. The source region is $1 \mathrm{~cm}$ long, and the resonance region is $10.5 \mathrm{~cm}$ long. The timing for the trapped drift experiments was done with a Parr CW-1 boxcar averager. In the trapped drift experiments, the ions are formed and are allowed to react before they are detected [11]. The reactants entered the ICR cell through Varian variable leak valves (Model 951-5700) to maintain a constant pressure and ratio of reactants. The pressures were measured with an ionization gauge and were of the order of $10^{-6}$ torr. Ionization gauge pressures were converted to actual pressures using literature values for relative sensitivities [12]. The temperature of the ICR cell was approximately $25^{\circ} \mathrm{C}$.

Additional trapped drift experiments were performed on an unmodified Nicolet (FTMS-2000) Fourier transform ICR spectrometer.

Chemicals were acquired from several commercial sources and were used as obtained. Mass spectral experiments showed no significant amounts of impurities.

\section{Results and Discussion}

Two distinct mechanisms were recently demonstrated for the formation of trimethylsilyl adduct ions of ethers [6]. In the case of dialkyl ethers, a number of experimental techniques showed the presence of a reactive intermediate ion and the formation of the adduct ion 


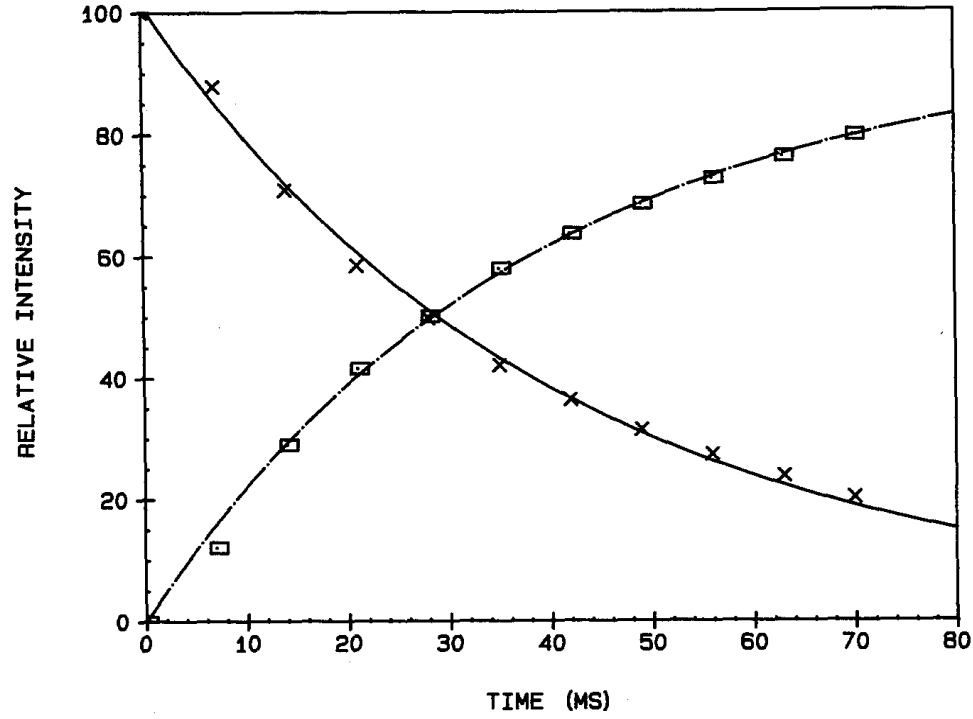

Figure 1. Time dependence of ionic abundances for a 1:1 mixture of TMS and acetone. $P \approx 2 \times 10^{-6}$ torr, $25^{\circ} \mathrm{C}$. Ions: $\times$, trimethylsilyl ion; $\square$, adduct ion. by consecutive ion-molecule reactions; however, simple bimolecular addition was proposed for the formation of the trimethylsilyl adduct of anisole [6].

A series of trapped drift experiments was performed on the reaction of trimethylsilyl ions with acetone, for which typical data are plotted in Figure 1. The absence of any intermediate ions and the shapes of these curves indicate that the adduct ions are formed by collisionally or radiatively stabilized addition reactions. Analogous curves were obtained from experiments on mixtures of tetramethylsilane with higher ketones and with phenol. The estimated time between collisions is $30 \mathrm{~ms}$ in these experiments, $\left[P \approx 1 \times 10^{-6}\right.$ torr, $T \approx 300 \mathrm{~K}$, and $k \approx 1 \times 10^{-9} \mathrm{~cm}^{3} /$ (molecule.s)]; consequently, the complexes are stable with respect to dissociation for at least that long. This lifetime suggests that the complexes may be stabilized by radiative processes.

A difference between collisional stabilization (eqs $2 a$ and $2 b$ ) and radiative stabilization (eq 3 ) can be seen by the kinetic analysis of reactions 1-3.

$$
\begin{gathered}
\frac{d\left[73^{+}\right]}{d t}=-k_{1}\left[73^{+}\right][\mathrm{M}]+k_{-1}\left[[\mathrm{M}+73]^{+*}\right] \\
\frac{d\left[[\mathrm{M}+73]^{+*}\right]}{d t}=k_{1}\left[73^{+}\right][\mathrm{M}] \\
-\left(k_{-1}+k_{\mathrm{r}}+k_{\mathrm{c}}[\mathrm{M}]+k_{\mathrm{c}}^{\prime}[\mathrm{TMS}]\right)\left[[\mathrm{M}+73]^{+*}\right]
\end{gathered}
$$

A steady-state approximation on $\left[(M+73)^{+*}\right]$ in eq 5 gives

$$
\left[[\mathrm{M}+73]^{+*}\right]_{\mathrm{ss}}=\frac{k_{1}\left[73^{+}\right][\mathrm{M}]}{k_{-1}+k_{\mathrm{r}}+k_{\mathrm{c}}[\mathrm{M}]+k_{\mathrm{c}}^{\prime}[\mathrm{TMS}]}
$$

Substitution of $\left[[\mathrm{M}+73]^{+*}\right]_{\mathrm{ss}}$ from eq 6 into eq 4 gives eq 7 for the formation of the stable adduct ion:

$$
\frac{d\left[73^{+}\right]}{d t}=-k_{1} \frac{\left(k_{\mathrm{r}}+k_{\mathrm{c}}[\mathrm{M}]+k_{\mathrm{c}}^{\prime}[\mathrm{TMS}]\right)\left[73^{+}\right][\mathrm{M}]}{k_{-1}+k_{\mathrm{r}}+k_{\mathrm{c}}[\mathrm{M}]+k_{c}^{\prime}[\mathrm{TMS}]}
$$

Integration of eq 7 yields an equation for the concentration of the trimethylsilyl ion as a function of time,

$$
\left[73^{+}\right]=\left[73^{+}\right]_{0} \exp \left(-k_{\mathrm{a}}[\mathrm{M}] t\right)
$$

in which $k_{\mathrm{a}}$ is the apparent second-order rate constant for the disappearance of the trimethylsilyl ion,

$$
k_{\mathrm{a}}=\frac{k_{1}\left(k_{\mathrm{r}}+k_{\mathrm{c}}[\mathrm{M}]+k_{\mathrm{c}}^{\prime}[\mathrm{TMS}]\right)}{k_{-1}+k_{\mathrm{r}}+k_{\mathrm{c}}[\mathrm{M}]+k_{\mathrm{c}}^{\prime}[\mathrm{TMS}]}
$$

Stabilization by a sample molecule, $M$, is expected to be more efficient than collisional stabilization by a TMS molecule because trimethylsilyl ion transfer should be an effective means of energy transfer. Therefore, because the pressures of M and TMS are approximately equal, one may tentatively neglect collisional stabilization by TMS.

If collisional stabilization by sample molecules is the predominant pathway that forms the trimethylsilyl adduct ions, that is, $k_{\mathrm{c}}[\mathrm{M}] \gg k_{\mathrm{r}}$, then the equation for $k_{\mathrm{a}}$ can be simplified to produce eq 10a and rearranged to give eq $10 \mathrm{~b}$.

$$
k_{\mathrm{a}}=k_{1}\left(k_{\mathrm{c}}[\mathrm{M}]\right) /\left(k_{-1}+k_{\mathrm{c}}[\mathrm{M}]\right)
$$




$$
\frac{1}{k_{\mathrm{a}}}=\frac{k_{-1}}{k_{1} k_{\mathrm{c}}}\left(\frac{1}{[\mathrm{M}]}\right)+\frac{1}{k_{1}}
$$

Equation 10a indicates a dependence of the apparent second-order rate constant, $k_{\mathrm{a}}$, on pressure or concentration, and eq $10 \mathrm{~b}$ indicates a linear relationship between $1 / k_{\mathrm{a}}$ and $1 /[\mathrm{M}]$.

On the other hand, if radiative stabilization is dominant, that is, $k_{\mathrm{r}} \gg k_{\mathrm{c}}[\mathrm{M}]$, then eq 9 can be simplified to give

$$
k_{\mathrm{a}}=k_{1} k_{\mathrm{r}} /\left(k_{-1}+k_{\mathrm{r}}\right)
$$

The apparent second-order rate constant derived for this mechanism is independent of pressure.

Therefore, the pressure dependence of the apparent second-order rate constant, $k_{\mathrm{a}}$, can be used to distinguish between these two mechanisms, collisional (eq 2a) stabilization and radiative (eq 3 ) stabilization. The apparent rate constants are obtained from the data for the relative abundance of the trimethylsilyl ion versus time as displayed in Figure 1. The results are given in Table 1. There is no obvious variation of $k_{\mathrm{a}}$ with pressure. The plot of $1 / k_{\mathrm{a}}$ versus $1 /[\mathrm{M}]$ (Figure 2 ) also shows no significant pressure variation, indicating direct addition of the trimethylsilyl ion with radiative stabilization to form adduct ions, reaction 3 .

The experimental rate constants were obtained with two different ICR mass spectrometers. The four rate constants at low acetone pressures were measured with a Nicolet FT 2000 FTMS with a TMS pressure of $\sim 1 \times 10^{-7}$ torr. The other three values were acquired on a home-made ICR mass spectrometer described
Table 1. Rate constants for the addition of the trimethylsilyl ion to acetone ${ }^{\mathrm{a}}$

\begin{tabular}{lc}
\hline Acetone pressure $\left(10^{-7}\right.$ torr $)$ & $k_{\mathrm{a}}\left[10^{-10} \mathrm{~cm}^{3} /(\right.$ molecule $\left.\cdot \mathrm{s})\right]$ \\
\hline 3.4 & 21 \\
4.1 & 14 \\
7.5 & 21 \\
9.8 & 19 \\
26 & 20 \\
39 & 16 \\
52 & 18 \\
Average & $18.4 \pm 2.6$ \\
Theoretical & \\
Langevin (see ref 15). & 11 \\
Su and Chesnavich [16] & 26 \\
Ridge [17] & 26 \\
\hline
\end{tabular}

a Experiments were performed on two different ICR mass spectrometers at $25^{\circ} \mathrm{C}$. The experiments at the four lowest acetone pressures were performed on a Nicolet FT 2000 FTMS; $P$ (TMS) $=1.0 \times 10^{-7}$ torr. The highest pressure experiments were performed on a home-made ICR spectrometer $[9-11] ; P($ TMS $)=1.0 \times 10^{-6}$ torr. Acetone pressures were corrected using the sensitivity data of ref 12 .

Polarizability calculated according to ref 13 . Dipole moment taken from ref 14.

above with a TMS pressure of $1 \times 10^{-6}$ torr. The apparent second-order rate constants, $k_{\mathrm{a}}$, do not vary significantly with a factor of 10 change in the pressure of TMS: $19 \pm 3 \times 10^{-10} \mathrm{~cm}^{3} /($ molecule.s $)$ at $P$ (TMS) $=$ $1.0 \times 10^{-7}$ torr and $18 \pm 2 \times 10^{-10} \mathrm{~cm}^{3} /$ (molecule.s) at $P($ TMS $)=1.0 \times 10^{-6}$ torr. Hence, collisional stabilization of $[M+73]^{+*}$ by TMS (reaction $2 b$ ) is, indeed, negligible, as assumed above.

One notes in Table 1 that the second-order rate con-
Figure 2. $1 / k_{\mathrm{a}}$ versus $1 / \mathrm{P}$ (acetone) for the addition of trimethylsilyl ions to acetone molecules, $25{ }^{\circ} \mathrm{C}$.

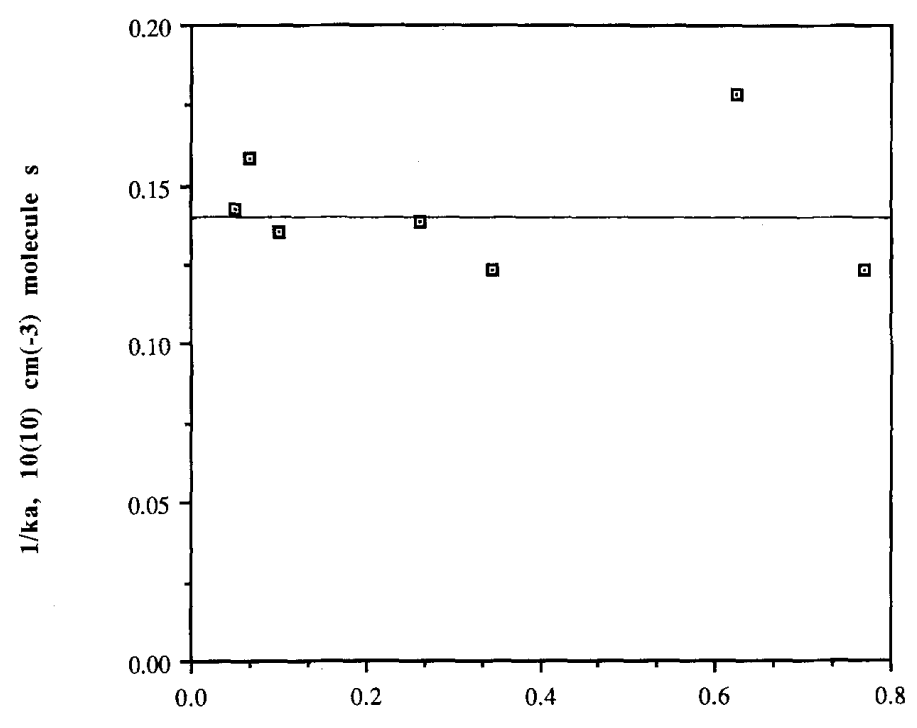

1/P(Acetone), 10(7) torr(-1) 
stant is somewhat smaller than the calculated collision rate constants $(70 \pm 10 \%)$. This observation implies that $k_{-1} \ll k_{\mathrm{r}}$. That is, the first-order rate constant for radiation is 2-4 times greater than that for decomposition to reactants at room temperature.

Radiative relaxation has been theoretically determined to be a major process for the stabilization of excited ions [18]. Radiative association reactions have been recognized as important in chemical evolution in the interstellar medium [19]. The association of $\mathrm{CH}_{3}^{+}$ with $\mathrm{H}_{2}$ to form $\mathrm{CH}_{5}^{+}$has also been experimentally determined to proceed by radiative stabilization at low temperatures [20]. Radiative association reactions have recently been reported for several systems: $\mathrm{F}^{-}+\mathrm{BF}_{3}$ [21], $\mathrm{CH}_{3}^{+}+\mathrm{SO}_{2}$ [22], and the formation of protonated dimers of dimethyl ether, diethyl ether, and acetonitrile [23]. The proposed radiative stabilization of the excited trimethylsilyl ion-acetone collision complex is consistent with these earlier observations. Rate constants for radiative decay for a number of radical ions of substituted benzenes have been measured [24]. The lifetimes for radiative decay for these species vary from tens to hundreds of milliseconds. This range of lifetimes covers the values necessary for radiative stabilization of these trimethylsilyl-acetone adduct ions.

The formation of long-lived complexes with the trimethylsilyl ion and simple ketones, phenol, and anisole at first appears to contradict the observations of extremely short lifetimes of the trimethylsilyl complexes of aliphatic alcohols and alkyl ethers. In these latter cases, the lifetimes of the excited collision complexes were estimated to be less than $10^{-7} \mathrm{~s}$, because no collisional stabilization was noted in the highpressure chemical ionization experiments. For the compounds discussed here, the lifetimes were demonstrated to be much longer, at least several millisec- onds. The difference in stabilities can be explained by the ability of the collision complex to decompose by an exothermic process.

There appear to be no exothermic ion-molecule reactions between the trimethylsilyl ion and acetone except solvation (see Figure 3). The proton (eq 12) and methide (eq 13) transfer reactions,

$$
\begin{aligned}
&\left(\mathrm{CH}_{3}\right)_{3} \mathrm{Si}^{+}+\left(\mathrm{CH}_{3}\right)_{2} \mathrm{CO} \rightarrow\left(\mathrm{CH}_{3}\right)_{2} \mathrm{COH}^{+} \\
&+\left(\mathrm{CH}_{3}\right)_{2} \mathrm{SiCH}_{2} \\
&\left(\mathrm{CH}_{3}\right)_{3} \mathrm{Si}^{+}+\left(\mathrm{CH}_{3}\right)_{2} \mathrm{CO} \rightarrow \mathrm{CH}_{3} \mathrm{CO}^{+}+\left(\mathrm{CH}_{3}\right)_{4} \mathrm{Si}
\end{aligned}
$$

are endothermic by 28 and $12 \mathrm{kcal} / \mathrm{mol}$, respectively. The dehydration reaction,

$$
\left(\mathrm{CH}_{3}\right)_{3} \mathrm{Si}^{+}+\left(\mathrm{CH}_{3}\right)_{2} \mathrm{CO} \rightarrow\left(\mathrm{CH}_{3}\right)_{3} \mathrm{SiOH}_{2}^{+}+\mathrm{CH}_{3} \mathrm{CCH}
$$

is also endothermic, $\Delta H_{\mathrm{r}}=9 \mathrm{kcal} / \mathrm{mol}$. Consequently, one may see from the schematic potential energy diagram shown in Figure 3 that the loss of only a small amount of energy from the collision complex would be sufficient to prevent rapid decomposition to the original reactants, $\left(\mathrm{CH}_{3}\right)_{3} \mathrm{Si}^{+}$and $\left(\mathrm{CH}_{3}\right)_{2} \mathrm{CO}$.

In contrast, for the reaction of the trimethylsilyl ion with 2-propanol, however, there are two exothermic reactions in addition to solvation: hydroxide abstrac-

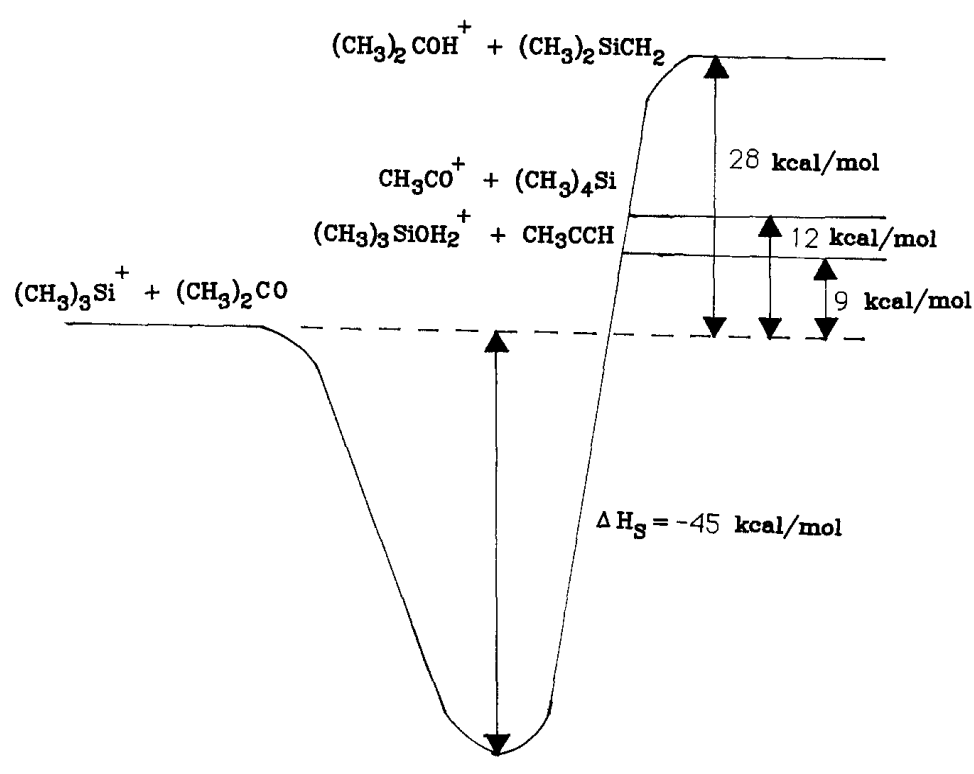

Figure 3. Schematic potential energy diagram for reactions of the trimethylsilyl ion with acetone. All values for the heats of formation are taken from ref 25, except for $\Delta H_{\mathrm{f}}\left[\left(\mathrm{CH}_{3}\right)_{3} \mathrm{Si}^{+}\right]=140 \mathrm{kcal} / \mathrm{mol}$, which is taken from ref $26 . \Delta H_{\mathrm{s}}=-45 \mathrm{kcal} / \mathrm{mol}$ for the addition of the trimethylsilyl ion to acetone [27]. 
Figure 4. Schematic potential energy diagram for reactions of the trimethylsilyl ion with 2propanol. All values for the heats of formation were taken from ref 25, except for $\Delta H_{\mathrm{f}}\left[\left(\mathrm{CH}_{3}\right)_{3} \mathrm{Si}^{+}\right]=140 \mathrm{kcal} / \mathrm{mol}$, which is from ref 26. $\Delta H_{\mathrm{s}}=-44 \mathrm{kcal} / \mathrm{mol}$ for the addition of the trimethylsilyl ion to 2-propanol [27].

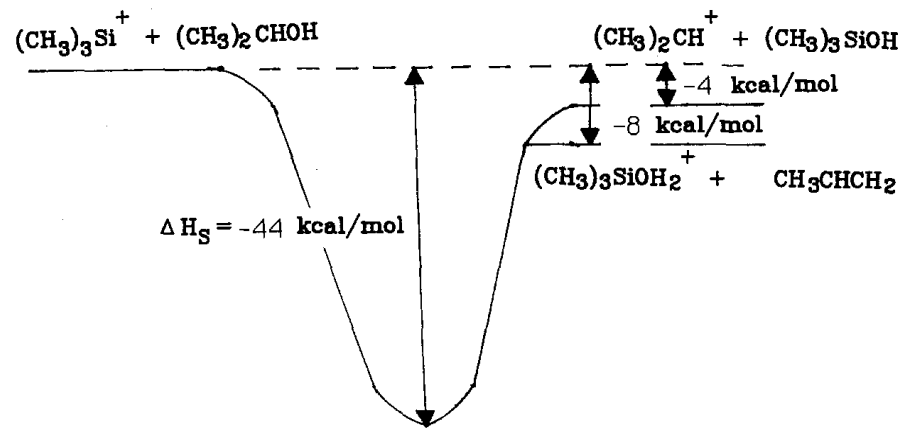

tion (eq 15) and dehydration (eq 16) (see Figure 4).

$$
\begin{aligned}
\left(\mathrm{CH}_{3}\right)_{3} \mathrm{Si}^{+}+\left(\mathrm{CH}_{3}\right)_{2} \mathrm{CHOH} \rightarrow & \left(\mathrm{CH}_{3}\right)_{2} \mathrm{CH}^{+} \\
& +\left(\mathrm{CH}_{3}\right)_{3} \mathrm{SiOH}(15) \\
\left(\mathrm{CH}_{3}\right)_{3} \mathrm{Si}^{+}+\left(\mathrm{CH}_{3}\right)_{2} \mathrm{CHOH} \rightarrow & \left(\mathrm{CH}_{3}\right)_{3} \mathrm{SiOH}_{2}^{+} \\
& +\mathrm{CH}_{2} \mathrm{CHCH}_{3}(16)
\end{aligned}
$$

These reactions are exothermic by 4 and $8 \mathrm{kcal} / \mathrm{mol}$, respectively. Consequently, from the schematic potential energy diagram shown in Figure 4, one sees that a large amount of energy must be internally distributed, radiated, or collisionally removed to stabilize this collision complex.

\section{Acknowledgment}

This work was supported by grant CHE 8412954 from the National Science Foundation.

\section{References}

1. Odiorne, T. J.; Harvey, D. J.; Vouros, P. J. Phys. Chem. 1972, $76,3217$.

2. Odiorne, T. J.; Harvey, D. J.; Vouros, P. J. Org. Chem. 1973, $38,4274$.

3. Blair, I. A.; Bowie, J. H. Aust. J. Chem. 1979, 32, 1389.

4. Clemens, D.; Munson, B. Org. Mass Spectrom. 1985, 20, 368.

5. Orlando, R.; Strobel, F.; Ridge, D. P.; Munson, B. Org. Mass Spectrom. 1987, 22, 597.

6. Orlando, R.; Ridge, D. P.; Munson, B. Org. Mass Spectrom. 1988, 23, 527.
7. Clemens, D.; Munson, B. Anal. Chem. 1985, 57, 2022.

8. Allison, J.; Ridge, D. P. J. Am. Chem. Soc. 1979, 101, 4998.

9. Wronka, J.; Ridge, D. P. Rev. Sci, Instrum. 1982, 53, 491.

10. Wronka, J.; Ridge, D. P. Int. J. Mass Spectrom. Ion Processes 1982, 43, 23.

11. McMahon, T. B.; Beauchamp, J. L. Rev. Sci. Instrum. 1972, $43,509$.

12. Bartmess, J.; Georgiadis, R. Vacuum 1983, 33, 149.

13. Le Fevre, R. J. W. Rev. Pure Appl. Chem. 1970, $20,67$.

14. McClellan, A. Tables of Experimental Dipole Moments; Freeman: San Francisco, 1963.

15. Harrison, A. G. Chemical Ionization Mass Spectrometry; CRC: Boca Raton, FL, 1983.

16. Su, T,; Chesnavich, W. J. Chem. Phys. 1982, 76, 5183.

17. Ridge, D. P. In Structure/Reactivity and Thermochemistry of Ions; Ausloos, P.; Lias, S. G., Eds.; Reidel: Boston, 1987, $\mathrm{p} 1$.

18. Gardiner, W. C., Jr, Rates and Mechanisms of Chemical Reactions; Benjamin/Cummings: Menlo Park, CA, 1972.

19. Black, J. H.; Dalgarno, A. Astrophys. J. Suppl. 1977, 54, 405.

20. Barlow, S. E.; Dunn, G. H.; Schauer, J. Phys. Rev. Lett. 1984, $52,902$.

21. Herd, C. R.; Babcock, L. M. J. Phys. Chem. 1987, 91, 2372.

22. Pentecost, T. C.; Babcock, L. M. Presented at the 37th ASMS Conference on Mass Spectrometry and Allied Topics; Miami Beach, FL, May 21-26, 1989.

23. Fisher, J. J.; McMahon, T. B. Presented at the 37 th ASMS Conference on Mass Spectrometry and Allied Topics; Miami Beach, FL, May 21-26, 1989.

24. Dunbar, R. C.; Chen, J. H.; So, H. Y.; Asamoto, B. J. Chem. Phys. 1987, 86, 2081.

25. Lias, S. G.; Liebman, J. F,; Levin, R. D. J. Phys. Chem. Ref. Data 1984, 13, 695.

26. Orlando, R.; Allgood, C.; Munson, B. Int. J. Mass Spectrom. Ion Processes 1989, 92, 93.

27. Wojtyniak, A. C. M.; Stone, J. A. Int. J. Mass Spectrom. Ion Processes 1986, 74, 59. 